\title{
PLATÃO E ALGUNS MITOS QUE LHE ATRIBUÍMOS
}

Miguel SPINELLI ${ }^{1}$

- RESUMO: Não é objetivo deste estudo investigar os mitos que Platão supostamente inventou, e, sim, os que (na tentativa de interpretar a sua obra) foram inventados sobre ele: conviç̧ões que lhe foram atribuídas e que não são dele, mas de outras crenças que buscaram nas dele justificativa e amparo. Dois desses mitos são neste estudo analisados com maior destaque: um, aquele que diz que "Platão fez do corpo um inimigo da alma"; outro, que "Platão refuta a percepção sensível".

- PALAVRAS-CHAVE: Platão, conhecimento, kátharsis, empiria, noêmas.

Existem vários mitos criados em torno de Platão, dentre eles o maior consiste em dizer que ele fez do corpo um inimigo da alma e que, nesse contexto, tentou demonstrar que os sentidos se opõem ao intelecto. Mais do que um mito - algo do qual jamais conseguimos nos livrar, afinal, os mitos persistem -, o que se criou, a par ou mesmo à revelia do platonismo, foram outras intenções semânticas com o propósito de construir distintos itinerários teóricos. ${ }^{2}$ A tradição escolástica foi a principal fonte dessas criações, sobretudo de mal-entendidos, e a sua influência tem se mantido na vida escolar até nossos dias. Tanto é verdade, que numa avaliação em que solicitava aos alunos que comentassem um trecho do Fédon de Platão,

1 Professor do Departamento de Filosofia e do Programa de Pós-Graduação em Filosofia da Universidade Federal de Santa Maria/RS. Artigo recebido em mar/07 e aprovado para publicação em jul/07.

2 Dedicamos duas obras nesse sentido, Spinelli, 1998 e 2007a. A Filosofia promove convicções que alimentam mitos; mito, nesse caso, é tudo aquilo que o intelecto toma como verdadeiro antes e depois da demonstração (do exercício do juízo). 
um deles (calouro e pouco freqüentador das aulas), saiu-se com esta preciosidade: "Me recuso a comentar. Esse Platão é muito medieval prô meu gosto". Este era o trecho:

É uma coisa bem conhecida dos amigos do saber, que sua alma, quando foi tomada sob os cuidados da filosofia, se encontrava completamente acorrentada a um corpo e como que colada a ele; que o corpo constituía para a alma uma espécie de prisão, através da qual ela devia forçosamente encarar as realidades, ao invés de fazê-lo por seus próprios meios e através de si mesma. (Fédon, 82d; cf. Platão, 1983)

A súmula do comentário previa que o aluno destacasse alguns dados, por exemplo, que, segundo Platão, quem se exercita na lida teórica: a) deveria ter um certo controle sobre o excesso de força ou alto teor de sedução que o sensível, de sólito, exerce sobre a mente humana; b) deveria desembaraçar o mais possível o intelecto do mundo das aparências, restringindoo ao que é inteligível; c) levar o intelecto a trabalhar com "seus próprios meios e através de si mesmo" (mediante noêmas, idéias, noções ou conceitos). O aluno poderia dizer mais coisas, por exemplo, que Platão, no Fédon, busca de vários modos demonstrar que os impulsos do corpo (sede das afecções sensíveis) são sempre muito mais inquietantes e fortes do que os desejos da alma (sede do intelecto e das inquirições teóricas); muitas vezes são até mesmo mais sedutores e apreciáveis. Platão diz, inclusive, que "todo prazer e sofrimento possuem como que uma espécie de crivo com o qual pregam a alma ao corpo, fazendo, assim, com que ela se torne matéria e passe a julgar da verdade das coisas conforme as indicações do corpo" (Fédon, 83d; cf. Platão, 1991). Nessas ocasiões, a alma (sede da inteligência e das volições) fica colada a ele, e o intelecto se materializa, de tal modo que perde o seu domínio ou capacidade natural de raciocínio. A alma passa a julgar (a exercitar o juízo) mediante as indicações do corpo e não por seus próprios meios.

Platão, ao contrário do que em geral se diz, concebe a alma bem mais unida do que separada do corpo, como se ela estivesse constantemente compelida a unir-se a ele. Constrita por certas impulsões ou paixões afetivas do corpo, como, por exemplo, por uma sensação de fome, ou por um desejo de prazer, ou por uma dor qualquer, a alma sempre solícita acorre a atendê-las. A relação entre a alma e o corpo se dá de modo semelhante a que um tal de Hisdosus Scholaticus (em suas anotações ao Comentário de Calcídio sobre o 'Timeu' de Platão) supôs entre a aranha e a sua teia: "Assim como a aranha, instalada no centro da teia, sente logo quando uma mosca rompe um fio, e por isso acorre rapidamente como que aflita pelo rompimento, do mesmo modo a alma do homem, ferida alguma parte do corpo, 
depressa acode quase não tolerando a lesão do corpo ao qual está firme e harmoniosamente unida". ${ }^{3}$

Platão parte de um pressuposto muito difundido entre os filósofos gregos (e que ainda hoje persiste): o de que a maioria dos humanos tem uma enorme dificuldade em exercitar (pôr em marcha) o próprio cérebro. Ocorre que para isso carecem de iniciativa, de muito estudo, de disciplina e de uma permanente dedicação. Isso é custoso, enquanto que as impulsões afetivas corporais são em geral espontâneas, promovem a maior parte das inquietações, levando a maioria a ocupar-se com elas, e não em filosofar (em se ilustrar ou instruir-se). A maioria, com efeito, aplica de algum modo o intelecto, porém, não no que mais importa, na busca do maior de todos os bens, a sabedoria, a educação da razão e a qualificação do humano. Todos se voltam preferencialmente para a administração de seus próprios impulsos, de suas tensões afetivas, das riquezas ou da pobreza, e de muitos outros males e bens. Eis aí, justamente, porque Platão exortava seus discípulos, em especial aqueles que se dispunham a filosofar, sobre a eminente necessidade de se libertarem das "amarras do sensível", e que, portanto, promovessem uma certa ascese das afecções, mas não a ponto de eliminar por completo a potência ou capacidade humana natural de afetar-se; pois, afinal, ninguém pode deixar de alimentar-se, assim como de uma dor de dentes ninguém está livre! Se bem que com fome e com dor de dentes (também esse é um outro lado importante da questão), fica difícil de filosofar!

Para Platão, todavia, não existem prazeres ou sofrimentos do corpo, e sim, prazeres e sofrimentos dos quais o corpo é o meio pelo qual a alma se submete. De todas, a principal característica da ascese libertadora é a sua intenção gnosiológica. Platão a ideou com uma finalidade precisa: oferecer aos membros da Academia indicações de como aprimorar a capacidade intelectiva da razão no desempenho cognoscitivo. Tudo indica que ele estava plenamente ciente de que a razão, por sua natureza, está sempre à mercê das afetações sensíveis e das inclinações dos sentimentos (das paixões afetivas), e, quanto menos educada, maior a dependência. Foi com a preocupação de educá-la que procurou mostrar aos acadêmicos, sob vários aspectos, os inconvenientes das impulsões sensíveis e o quanto elas dificultam a absorção ou elevação da mente no desempenho filosófico: na meditação teórica ou, sobretudo, na investigação não-empírica. Tendo observado que,

3 "Sic <ut> aranea, ait, stans in medio telae sentit, quam cito musca aliquem filum suum corrumpit itaque illuc celeriter currit quasi de fili perfectione dolens, sic hominis anima aliqua parte corporis laesa illuc festine meat quasi impatiens laesionis corporis, cui firme et proportionaliter iuncta est" (Hisdosius Scholaticus, ad Chalcidium in Platonis Timaeum, codex Parisinus 1, 8642, s. XII, f. 2; DK 22 B 67); Fonte DK: Diels \& Kranz, 1989. 
delas, somos como que espontaneamente submissos, que o corpo é o seu suporte material, então era dele que a alma deveria forçosamente libertarse, voltando-se sobre si mesma, a fim de obter sucesso na reflexão teórica. Afinal, pergunta-se Platão, "não é no ato de raciocinar <logízesthai>, e não de outro modo que a alma apreende algo a respeito do que existe <tôn óntôn>?". E responde: "É obvio que ela raciocina melhor se livre de qualquer empecilho: do ouvido, da vista, de um sofrimento ou sobretudo de um prazer..." (Fédon, 65c; cf. Cobb-Steven, 1989; Cooper, 1970; Day, 1997; Naknikian, 1955). Até mesmo "as aves não cantam (acrescenta), caso tenham fome, frio, ou se padecem de algum tipo de sofrimento..." (Fédon, 85a).

Nesse, como em outros trechos, Platão jamais afirma que o sensível (o mundo dos fenômenos, do que é visível, audível, etc.) é destituído de utilidade ou de qualquer valor no processo cognoscitivo. A questão que a ele se impôs era totalmente outra, e a sua proposta filosófica (a sua ascese) tinha uma finalidade educadora, e não condiz evidentemente com uma negação pura e simples do mundo fenomênico, porque seria banal. A elevação fundamental de sua ascese <kátharsis> libertadora tinha (e ainda indica), como momento supremo do ato raciocinativo, um exercício de concentração: aquele pelo qual a "alma filosófica" se afaz à meditação em busca da plenitude do conhecimento. Eis o que Platão, nesse sentido, recomendava a seus ouvintes e discípulos:

recomendo-lhes que se concentrem e se voltem para si (...), que se persuadam de que as realidades examinadas por intermédio do corpo não são em si mesmas verdadeiras, pois pertencem ao gênero do sensível e do visível, e o que é examinado pela alma, e por seus próprios meios, é, ao mesmo tempo, inteligível e invisível. (idem, 84b)

A proposta filosófica de Platão não tem só um, mas vários propósitos: a) pôr em questão a falsa crença de que o testemunho do sensível por si só é confiável (tem valor de ciência); b) demonstrar que a investigação do que é (da realidade, do ser ou do existente de fato), vai bem além da coisa mesma, empiricamente considerada. Dela "apreendemos (somente) algo <gígnetai ti>", e, portanto, do que é (tal como ensinara Demócrito) estamos distanciados. Mesmo assim, e por mais paradoxal que isto possa parecer, esse distanciamento é necessário; c) persuadir aos que se propunham a filosofar, que a Filosofia tem alguns setores próprios de investigação, por exemplo, o da edificação formal da ciência, do éthos humano e da vida cívica, que dispensam a experiência ou a empiria.

Sob vários aspectos, Platão não é o filósofo da observação e explanação teórica nem de fenômenos e nem da experiência vivida, mas o filósofo da experiência passível de ser racional ou idealmente construída. É por esse 
viés que ele orientou preferencialmente a sua investigação teórica, de modo que, por dedicar-se sobretudo à investigação da téchnê do pensamento produtivo e do êthos da vida cívica, não pressupôs (porque não tinha mesmo como pressupor) nenhum modelo empírico, como se deu, por exemplo, em seu diálogo sobre a República, dedicado a edificar racionalmente e mediante a explanação de conceitos, o Estado ideal. Ali, o princípio pelo qual orientou a sua investigação foi o seguinte: visto que a edificação racional de um Estado pressupõe conceitos tais como o que é bom, belo, justo, virtuoso, etc., e que todos esses conceitos independem da empiria (deles não há um arquétipo que dela possa ser retirado), então concluiu que era necessário empenhar-se em construí-lo. Em conseqüência, também foi levado a admitir que era necessário perguntar pelo que é bom, belo, justo, virtuoso, etc., "em si", e, portanto, buscar a respeito de cada um a sua "forma" pura, independentemente de qualquer referência a algo concreto, ou seja, de supostos atos de bondade, ou de ações virtuosas, ou de indivíduos ou coisas tidas como belas... Com efeito, concluiu também que se o bom, o belo, o justo, etc., são "algo", assim o são em dependência do pensamento e do discurso, porque, afinal, é o pensamento, mediante noêmas, que "dá ser à justiça, à sabedoria e a tudo o que se refere à virtude e a seus contrários, e finalmente à alma, na qual (esses seres) vem a residir..." (Sofista, 247b).

Há, no Fédon, um trecho que sintetiza bem o porquê de Platão atribuir à empiria valor secundário, ou, quando não, nenhum valor na investigação filosófica: "O que diremos de certas coisas (pergunta Sócrates a Símias), do justo, por exemplo, que é algo em si mesmo ou nada? - Por Zeus, diremos que é algo (respondeu Símias). E o mesmo não diremos também a respeito do que é bom e do que é belo (prosseguiu Sócrates)? - Sem dúvida. E alguma vez já viste com teus olhos coisas semelhantes? - Nunca. E será que tens algum sentido corporal pelo qual chegaste a apreciar (...), por exemplo, a grandeza, a sanidade, a força, em resumo, a substância <tês ousías> pela qual cada uma dessas coisas são em si mesmas?". Claro que não, respondeu Símias. Sendo assim, concluiu Sócrates, é então somente "pelo raciocínio que a alma chega a ver, se é que chega", todas essas coisas: o bom, o belo, o justo, a grandeza, a força, a sanidade, etc (cf. Fédon, 65d-66a). E é, por suposto, através do raciocínio, e não através da empiria, que todas essas coisas vêm a ser e passam a habitar a alma como realidades do inteligível.

O Fédon de Platão foi dedicado aos últimos momentos da vida de Sócrates. Concluído o julgamento, condenado, Sócrates foi encaminhado ao cárcere, onde esperou por um mês, antes que lhe fora dado beber a cicuta. A infusão lhe foi dada ao entardecer, servida num cálice, com pompa e requinte, como se isso qualificasse o ato! Assim que a bebida fatal lhe foi ofe- 
recida, perguntou ao carrasco: "Então, meu caro, tu que tens experiência, o que preciso fazer? Beber (respondeu ele), caminhar um pouco até que as pernas fiquem pesadas, depois deitar e aguardar o efeito" (Fédon, 117b). O efeito era demorado, levava horas (parece que, no máximo, seis): provocava, desde os pés, o enrijecimento muscular lento e progressivo, causando enfim a morte por asfixia. Era indolor, mas letal. Curiosamente, alguns comentadores louvam (pelo fato de ser indolor) a "humanidade" dos atenienses em suas execuções capitais.

Sócrates discute com Fédon e outros interlocutores presentes (Críton, Símias, Cebes), a tese da imortalidade. O Diálogo, porém, não se restringe a esse tema. Em seu conjunto, o Diálogo destaca outras questões relevantes, dentre elas, a do ideal de vida filosófica vivido por Sócrates, sempre dedicado à meditação teórica de questões não-empíricas. O Diálogo é uma descrição cuidadosa de como a alma (o aparato cognoscitivo), nos momentos em que produz conhecimento ou ciência, deveria se concentrar sobre si mesma, do modo assim como Sócrates, segundo consta no Diálogo, dava o exemplo: "Sócrates, isso se notava ao olhá-lo, tinha a mente completamente absorta na meditação do argumento que acabara de expor". A sua mente não se distraía do que estava investigando, e, bem por isso, era o bom exemplo da alma filosófica, da que produz saber, e da qual se pedem duas coisas: uma, que se concentre sobre si mesma, que ligue os seus passos aos do raciocínio, e que se mantenha sempre presente nele; outra, que tenha uma orientação ou meta, qual seja, que tome "o verdadeiro, o divino <theîon>, o que escapa à opinião, por espetáculo e também por alimento" (Fédon, 84a-b).

Por divino (essa é uma questão que precisa logo ser caracterizada quanto à sua intenção teórica originária), a dialógica platônica não supõe a existência de um ente real, algo que se possa empiricamente verificar. Por divino <tò theîon>, vem expresso, em um sentido amplo, um estágio além da percepção sensível, nível em que só o intelecto é capaz de ajuizar e de compreender. Quando Sócrates, por exemplo, no final do Críton, conclui dizendo que deveria seguir "o caminho indicado pela divindade <ho theós $>$ " (epeidêi taútêi ho theòs huphêgeitai; Críton. 54e), simplesmente estava ponderando a Críton que só havia um caminho a seguir: aquele que o exame racional, depois de averiguado todas as alternativas apresentadas sobre o tema em discussão, indicou como sendo a mais plausível ("já conheces o meu costume - diz Sócrates a Críton - de não me render a outras razões senão à unica que me pareça mais justa depois de examinar todas as apresentadas"; Críton. 46b). No próprio Fédon, como já visto, divino é sinônimo de verdadeiro, daquilo "que escapa à opinião" (Fédon, 84a), e que, bem por isso, diz respeito a um saber que só o intelecto, com seus próprios meios (ou seja, o exame da razão mediante noêmas) é capaz de promover e de acessar; noutro, divino corresponde a um momento de excelência do pensar: aquele 
pelo qual o intelecto se exerce sobre si mesmo, a ponto de ficar completamente absorto na meditação do que, argumentativamente, está investigando. Divino, nesse caso, também se refere a um estágio de elevação, próprio de quem se aplica ao estudo teórico: a aduzir raciocínios que vêm a se constituir numa argumentação ou dissertação teórica. Nesse sentido, divino é o momento indefectível da epistême filosófica, ou seja, da edificação da inteligibilidade humana como necessidade de dar explicações racionais plausíveis (com valor universal) ao que não se vê, sem que a ciência, a epistême filosófica, se restrinja à dóxa. Por isso, o divino corresponde ao que é inteligível: a tudo aquilo que pertence à esfera do pensamento ou do intelecto < do noûs> e do que por ele é passível de ser compreendido ou explicado mediante noêmas. Por esse ponto de vista, o divino vem a ser o que Platão denominou de "naturezas inteligíveis" <noeraîs phýseôs >, atinentes ao universo dos noêmas (dos pensamentos ou idéias, das noções ou conceitos), ou ainda ao que Platão genericamente denominou de kósmos noêtos, de "mundo inteligível".

As tais naturezas inteligíveis também foram por Platão chamadas de "naturezas divinas" <theías phýseos>, concebidas como sendo "realidades (entes) inteligíveis" que, como tais, eram tidas como theîon, ou seja, como sendo alheias ou fora do alcance imediato da percepção sensível, e que, bem por isso, eram inteligíveis. Tais entes ou realidades não eram tidas evidentemente como realidades em sentido próprio (como existentes de fato, a exemplo de como existe um toco ou qualquer tropeço no caminho), porém, como se fossem, pois são substratos teóricos, conceitos ou idéias (digamos, "objetos da ciência"), e, portanto, realidades discerníveis, com as quais a alma filosófica necessariamente deveria se ocupar. Dá-se que, para Platão, a realidade concreta, a dos entes existentes de fato, só resulta para nós em realidade na medida em que a convertemos em noêmas: em conceitos, noções ou idéias. Antes disso, a realidade empírica é "sombra": apenas aquilo que os sentidos nos fornece como sensações. Por isso, a realidade para nós, segundo ele, aquela a respeito da qual podemos pensar algo com sentido, mesmo no caso da explanação teórica a partir de fenômenos, são noêmas (idéas). Daí, enfim, porque o divino veio em última instância a designar o universo das eîdos: porque dizia respeito a tudo aquilo que só pode ser "visto" (tornar-se inteligível, arranjado feito um kósmos) pela via do símbolo e do pensamento, a ponto, como diz Platão (a exemplo do que ensinara Parmênides, que "pensar e ser é o mesmo"), de "o pensamento e o discurso" resultarem na "mesma coisa" (Sofista, 263e; DK 28 B3).

Foi, pois, sob os termos do kósmos noêtos (de "mundo inteligível") que Platão pôs em questão o lugar apropriado da ciência, da epistême filosófica. Era tido por ele como inteligível tudo aquilo que só o intelecto é capaz de conceber ou o que, a nível da noêsis, deixa-se submeter a um sistema ou 
arranjo de símbolos ou de relações lógicas. Platão concebeu a idéia de epistême referida à esfera do inteligível e não do sensível, simplesmente porque jamais admitiu (assim como nenhum dos grandes mestres) que a sensação é ciência. Nós não conhecemos, por exemplo, um objeto ou coisa <um tò ón> ou uma realidade <uma alethés > pelo simples fato de vê-la, nem tampouco imaginando algo sobre ela. Também não conhecemos as coisas pelo que se mostram, pelo devir das aparências, e, sim, pelo que nelas racionalmente (mediante símbolos ideativos) supomos como permanente, imóvel, sempre verdadeiro e idêntico a si mesmo. Seria tudo muito confuso, sobretudo injusto e pouco consolador, se tudo o que existe (a realidade, as coisas, o ser) mudasse em sua natureza todo dia ou constantemente e em todos os sentidos. Pois, se isso acontecesse, ficaríamos impossibilitados de saber o que algo é, ou o modo como ele existe em si mesmo. Portanto, a fim de que possamos saber algo a respeito de algo (de qualquer existente) é necessário, em primeiro lugar, que tal existente, em sua natureza e de algum modo (de ser), não esteja totalmente submisso ao devir; segundo, que esse seu modo de ser seja essencial e determinante por natureza e que, por convenção, venha a ser manifesto mediante signos explicativos ou de reconhecimento; terceiro, posto que é pela via do pensamento e do discurso, mediante signos, que damos ser ao que (por natureza) tem ser, no que diz respeito ao não-ser, a ele não se aplica sob nenhum aspecto esse princípio, porque, como disse Parmênides, o que não existe é imperscrutável, não pode ser "expresso em palavras" (verbalizado ou ideado racionalmente) (DK 28 B 2, 67), restando, pois, incognoscível.

A investigação filosófica com a qual Platão em particular se ocupou é caracterizadamente não-empírica. Foi talvez por ser um matemático que priorizou a explanação teórica mediante conceitos, em detrimento da experiência. Com efeito, foi ele certamente, dentre todos os filósofos, o primeiro a se dar conta de que nas ciências físicas ou naturais a experiência é dada de antemão, ao passo que nas "ciências humanas", sobretudo na Filosofia, na medida em que ela se ocupa com a edificação do éthos cívico e com a explanação da techné do fazer ciência, a experiência não é dada, mas pode e deve ser racional e conceitualmente construída: não uma experiência isolada ou particular, e, sim, unívocas, válidas para todos os seres racionais (comum a todos, com valor universal). Foi Platão também quem deixou bem claro que, mesmo as explanações teóricas a partir de fenômenos, só podem ser feitas mediante conceitos: porque não há como pensar as coisas existentes de fato sem antes nomeá-las, sem convertê-las em símbolos apropriados ao exercício do pensar. Por isso, a ascese por ele proposta previu 
elevação inclusive da empiria, mas, bem entendido, só naqueles casos em que a empiria não tem efeito, é dispensável.

A bem da verdade, o que Platão buscou, entre o sensível e o inteligível, se quiser entre a alma e o corpo, foi o seu equilíbrio, ou seja, visto que na maioria das vezes é o sensível que se impõe ao inteligível, é necessário em alguns momentos e sob certos propósitos, que o inteligível se imponha. Tendo, por exemplo, constatado que o estudo "feito por intermédio dos olhos, dos ouvidos e dos outros sentidos está inçado de ilusões" (Fédon, 83a), recomendava a seus discípulos que se "livrassem" deles, ou que deles evitassem servir-se, mas com a seguinte advertência: "pelo menos quando não houver uma imperiosa necessidade". De modo semelhante, quando ensinava que a alma deve "encarar as realidades por seus próprios meios e através de si mesma" logo advertia: "desde que se tenha examinado bem o que cada coisa é em si mesma" (ibidem). Nesse ponto específico, ou seja, no caso de alguém se propor a investigar, "a encarar as realidades", delas não poderia abster-se, ao contrário, carecia antes de bem examinar o que cada uma é enquanto realidade. Por certo ensinava a seus discípulos, em particular aos que se interessavam pelo estudo da História Natural (como era o caso de Aristóteles), que, por exemplo, se quisessem "encarar as realidades" da Botânica, não teriam como fazê-lo isolando-se em sua oikía, dentro de casa, e, sim, mantendo contato com o objeto de seu estudo, circulando pelos campos e jardins. ${ }^{4}$

Platão, pois, estava plenamente ciente de que existem certas esferas do saber que o sensível se impõe como "uma imperiosa necessidade". Por suposto ele também sabia (afinal, não era um tolo) o que todos sabemos: que o sensível, sob certos aspectos, é fonte privilegiada de algum saber. Por exemplo, como experimentamos que o fogo queima senão colocando o dedo no fogo? Como saberemos que um cafezinho fumegante estará quente ou frio, forte ou fraco? Como, afinal, saberíamos que o mundo é colorido? Das coisas visíveis, todos temos acesso ao que delas, através dos sentidos, percebemos; todavia, cada um dos nossos sentidos tem especificidades perceptivas que lhes são próprias. Os olhos, por exemplo, vêem formas (silhuetas) e cores, porém, não vêem, digamos, uma "árvore", porque árvore é simplesmente uma palavra ou símbolo do pensamento proferido: por ele evocamos ou nomeamos um algo existente, do qual vemos certas formas e cores, e ao qual denominamos de árvore, e assim para outras coisas, um toco, uma mesa, um homem, etc., e também em consonância com os demais

4 Referência ao Liceu, fundado por Aristóteles por volta de 335, em um ginásio próximo ao templo de Apolo Liceu, ornado de grandes jardins. Sabe-se que o Liceu não era propriedade de Aristóteles, mas um ginásio aberto a todos (cf. Düring, 1957, p.460-1). 
perceptos, por exemplo, ao que denominamos de doce, de amargo, liso, grave, etc.. Daí por adiante, para além da palavra ou signo de reconhecimento, tudo o que sabemos ou podemos saber a respeito de algo percebido, da árvore, por exemplo, sobre o tipo de resina, de celulose, de substâncias das quais se nutre, etc., resulta cada vez mais invisível, a ponto de termos que admitir como princípio verdadeiro o seguinte: que aquele que "mais vê" (o que os outros não vêem e o que só a inteligência é capaz de "ver") é o que "mais sabe". Invisíveis são também o belo, o bom, o justo, a grandeza, a saúde, a força, etc., realidades que só o "pensamento em si e por si mesmo, e sem mistura" (Fédon, 99c; cf. 66a: “... sem recorrer, no ato de pensar, nem à vista, nem a um outro sentido, ou sem levar nenhum deles à companhia do raciocínio") pode acessar.

Na prática, Platão deu preferência em suas investigações, às coisas divinas, mas isso não significa que, para ele, raciocinar fosse um imaginar ou que a realidade fosse pura invenção. As realidades, para ele, são noêmas (idéas), de modo que é função do símbolo expressar a verdade, ou seja, reconstituir a realidade mediante formas do dizer e do pensar. Daí porque a realidade, enquanto formas, não as encontramos na empiria (na qual se manifestam "sombras" do real), e sim, na mente. Só ela está em condições de "construir" cognoscitivamente o que é, tornar inteligível o real: "Que outras definições, estrangeiro (Platão dialogava com um eleata, discípulo de Parmênides) daríamos à imagem, se não a de um segundo objeto igual, copiado do verdadeiro?" (Sofista, 240a; cf. Patterson, 1985; Rabel, 1996; Ringbom, 1965). Não sendo as imagens o que é verdadeiro, mas cópias do real, então não são aquilo de que as coisas são em si mesmas, e sim, o que a respeito delas edificamos como sendo verdadeiro. Daí porque, em última instância, o filósofo, segundo Platão, é um construtor da verdade. Porém, não ao modo do sofista, que só não tem compromisso com o valor e o eco retórico das palavras. O filósofo, por ter compromisso com a verdade, toma em consideração o que é, ou, segundo as palavras de Platão, busca a "essência em si, aquela cuja existência afirmamos nas nossas perguntas e respostas, aquilo que permanece sempre a mesma e que mantém a sua identidade, que agora não é de um modo e logo depois de um outro" (Fédon, 78d).

Platão não só atribuiu ao ser (ao que é) os mesmo predicados que Parmênides, como também concebeu o que é (enquanto estrutura primordial do pensar e do discurso, cf. Spinelli, 1997) como um modo de perguntar e de responder, como sendo ao mesmo tempo afirmativo e interrogativo. Platão, com efeito, admitiu "duas formas de ser < dúo eídê tôn óntôn>, uma visível e outra invisível" (Fédon, 79a). Sob esses termos, visível e invisível, ele contrapôs o sensível ao inteligível, ou melhor, a observação da aparência do que se vê, ao exame atento do que não se vê, ou seja, do que "cada coisa é na sua essência" (cf. idem, 84 a-b: "Que as almas não creiam enfim senão no 
próprio testemunho desde que tenham examinado bem o que cada coisa é na sua essência..."). A "essência em si", como já ficou dito, tem a sua existência afirmada em nossas perguntas e respostas a respeito do que é, sendo que, para Platão, aquilo ao qual se pergunta pelo que é, necessariamente tem que ser algo, um nada é que não pode ser. Dá-se que, a respeito do que não existe, nada podemos dizer, e quem pensa no que não existe, pensa em nada (Sofista, 237e, 238c, 262e) -, ou, como disse Parmênides, no que diz respeito ao nada "sequer podemos nomeá-lo".

O que é tanto se refere a algo concreto, empiricamente reconhecido, quanto a algo abstrato, a realidades inteligíveis, cuja "entidade" só a razão, mediante noêmas, é capaz de acessar. "O que diremos da justiça - essa foi a pergunta de Sócrates a Símias -, que ela é alguma coisa ou nada?" - e esta foi a resposta: "diremos que é algo". Também o belo, o bom o justo, etc., segundo Platão, têm que ser pensado como sendo alguma coisa, nada (pelas razões acima aduzidas) é que não podem ser. Tudo ou toda investigação precisa se submeter ao princípio da ciência, qual seja, o da definição ou busca da forma única através da qual temos acesso ao todo: "crês que alguém (pergunta Sócrates a Mênon) sabe <eidénai> o que é uma parte da virtude sem que se saiba o que ela é?" (Mênon, 79c: "all'oíei tivà eidénai mórion apetês hóti estín, autên mê eidóta"). Se se quer saber algo a respeito da parte de um todo é forçosamente necessário ter uma compreensão do todo, ou seja, estar de posse de um princípio de unidade pelo qual se dá como sabido algo a respeito da parte. Por exemplo, se digo que a prudência (ou a justiça, ou a piedade) é uma virtude, estou igualmente afirmando que a prudência é uma parte da virtude, e, sendo assim, para que eu possa saber algo a respeito da parte careço saber o que é o todo, no caso, o que é a virtude em si. Eis nesse sentido (na medida em que, juntos, examinavam a prudência, a justiça, etc., como partes da virtude), o que Sócrates disse a Mênon: "procuro aquilo que é o mesmo em todas essas coisas" (Ménon, 75a).

A busca por um princípio de unidade e por aquilo que "é o mesmo" em todas as coisas (que se investiga), Platão estendeu não só a um, mas a todo tipo de investigação, tanto ao ser em sua forma visível, quanto invisível, às questões abstratas e aos fenômenos dados na empiria. Nesse último caso, do que é empírico, do que nos é dado como algo concreto, Platão se empenhou em demonstrar que dele nada saberemos com segurança se fiarmos tão-somente nas aparências; é necessário ir além, e assim devemos sair em busca do que não vemos, do ser verdadeiro: da forma <eídos> através da qual o que é, "é um em si e por si", sempre o mesmo, imutável em sua identidade, sem jamais permitir, em nenhuma parte de si mesmo e sob nenhum aspecto, a menor alteração. E aqui logo se vê que Platão atribuiu ao que é os mesmos predicados tal como Parmênides os concebeu: que "é imperecível, um todo inteiro, inabalável e sem fim" (DK 28 B 8, 3). 
Sob o termo eîdos, Platão indica o que se vê (a silhueta e os demais perceptos sensíveis que, para todos nós, têm algum valor objetivo), mas expressa sobretudo o que, dentro de certos limites e possibilidades, podemos objetivamente conhecer. Sob esse aspecto, em termos de conhecimento ou ciência, a eîdos não é aquilo de que a coisa é em si mesma, uma vez que a ciência requer a nomeação. Com efeito, Platão também pressupõe, enquanto eîdos, o mesmo princípio pré-socrático da phýsis, aquele pelo qual os primeiros mestres da Filosofia conceberam o seguinte dilema: de que, na Natureza, observamos movimento, devir, mudanças, no entanto, racionalmente, só podemos concluir ou pensar a imobilidade. Foi, com efeito, Zenão quem o resolveu, laçando mão de vários argumentos, a fim de demonstrar que o movimento aparente (observado), a razão não o pode provar, a não ser a imobilidade. Mas eis o pressuposto platônico: "é necessário que todos os seres permaneçam inabaláveis em sua identidade" (Fédon, 78d), que, sob algum aspecto (naquele que lhe é essencial, a eîdos enquanto ousía), por natureza se mantenha inalterável, sempre o mesmo, do início ao término de sua existência, a fim de que não haja tumulto no ser (e na existência). Ora, se tal princípio é válido e necessário quanto ao ser, também o é quanto ao conhecimento.

O processo de conhecer, ele o descreve na Alegoria da Caverna. Eis o processo: é preciso sair das sombras <tàs skías> em direção às imagens <eídôla> (que também de algum modo ainda são sombras, cf. República, 509e: "Chamo imagens, em primeiro lugar, as sombras"), das imagens à tessitura do saber, ao universo das coisas divinas ou das considerações sapientes <theásasthai>. É preciso também levar em conta (e isto aparece de modo claro em Platão), que o lugar do homem não é nem o da pura luz (que cega) e nem o da escuridão absoluta (em que, igualmente, nada se vê). Nem num nem noutro há visão. A boa visão humana é a que se dá mediante a posse de um requintado equilíbrio entre luz e escuridão, claro e escuro, luz e sombra (cf. República, 509e: "é em dependência de claridade e de obscuridade que, no mundo visível, tu terás, um primeiro seguimento, o das imagens"; e República, 508c: "Sabes que os olhos, quando se voltam para os objetos cujas cores já não são mantidas pela luz do dia (...), vêem mal e parecem quase cegos, como se não tivessem uma visão clara"). Todavia, quem se aventura em direção à luz não carece de recorrer à escuridão, porque se encontra permanentemente nela. O que tem a fazer é buscar um equilíbrio, a fim de que haja visão. Dado, com efeito, que de nossa condição humana não nos livramos (a kátharsis pressuposta por Platão é permanente), também do ser, do que é, da realidade que se mostra, jamais podemos nos livrar. Alçar-se ao mundo inteligível é sair em busca de luz, com um propósito bem específico: iluminar a escuridão humana, algo que só pode ser feito agregando-se ao ser, jamais sem ele. Porque não há como sermos hu- 
manamente melhores abstraindo-nos de nossa humanidade. Dela somos prisioneiros. Somos o que somos, do qual necessariamente precisamos bem saber, de modo que não há como edificar em nós o ser (homem), erradicando em nós a "humanidade". Carecemos, antes, de bem conhecê-la. Foi exatamente por isso que a filosofia grega fez do conhecer-se a si mesmo a sua principal tarefa. Entretanto, o conhece-te a ti mesmo (máxima concebida por Tales e adotada por Heráclito e Sócrates, cf. Spinelli, 2007b e 2005) se deu na Cultura grega em conseqüência de outra máxima primordial: Tenha coragem de ser homem não queira ser um Deus. Para ser homem fazia-se necessário autoconhecer-se: saber o que é ser homem e explorar dele os limites e possibilidades enquanto homem. Era indispensável que o indivíduo humano se auto-avaliasse, a começar pela sua própria capacidade de autoconhecimento, a nível teórico e prático. Eis aí por que a questão do conhecimento se transformou no tema fundamental da Filosofia grega e de toda a investigação filosófica posterior, até os nossos dias. Se bem que, hoje, está centrada em perspectivas distintas, não tanto na sondagem dos limites e possibilidades do aparato cognoscitivo (da faculdade de conhecer), e, sim, da capacidade humana de ser um indivíduo autêntico, ético, capaz de gerenciar seus medos, seus ressentimentos e anseios, e de, nesse emaranhado, promover explicações e valores racionais que dêem sentido à própria vida. Mas, hoje, como sempre, o maior desafio tem sido outro: levar os indivíduos a cultivar a boa disposição de retirar de si mesmos o próprio alimento, de garantir por si próprios a sua sobrevivência enquanto homem, sem tutela ou sem qualquer outro tipo de submissão desqualificadora de seu arbítrio.

SPINELLI, Miguel. Plato and some myths attributed to him. Trans/Form/Ação, (São Paulo), v.30(1), 2007, p.191-204.

- ABSTRACT: It is not the aim of this paper to investigate the myths which Plato invented, but to inquire into those which (in the attempt to interpret his works) were invented about him: claims which were attributed to him without being his own, and other beliefs which were held to be justified and supported by his claims. Two of these myths are analized with maior emphasis: first, that "Plato made the body an enemy of the soul"; second, that "Plato rejected sensible perception".

- KEYWORDS: Plato, Knowledge, kátharsis, experience, noêmas. 


\section{Referências bibliográficas}

COBB-STEVENS. "Perception, Appearance and Kinesis. The Secret Doctrine in Plato's Theaetetus". In: ANTON, J. \& PREUS, A. (Eds.). Essays in Ancient Greek Philosophy III, N. York, 1989.

COOPER, John M.. "Plato on Sense-Perception and Knowledge (Theaetetus 184186)". Phronesis XV (1970) 2.

DAY, Jane. "The Theory of Perception in Plato's Theaetetus 152-183". In: TAYLOR, C.W. (ed.). Oxford Studies in Ancient Philosophy. v.XV. Oxford: Clarendon, 1997.

DIELS, Herman \& KRANZ, Walther. Die Fragmente der Vorsokratiker. 18 ${ }^{a}$ ed., (Unveränderter Nachdruck der 6. Auflage 1951). Zürich-Hildesheim: Weidmann, 1989.

DÜRING, Ingemar. Aristotle in the ancient bibliographical tradition. Göteborg, 1957.

NAKNIKIAN, George. "Plato's Theory of Sensation. I - II". Review of Metaphysics IX, 1-2. 1955.

PATTERSON, R. Image and Reality in Plato's Metaphysics. Indianapolis: Hackett Publishing, 1985.

PLATÃo. Fédon. Tradução de Jorge Paleikat e João Cruz Costa. Coleção Os Pensadores. São Paulo: Abril Cultural, 1983.

PLATO. Phaidon. Übersetzt und herausgegeben von Barbara Zehnpfennig. Hamburg: Meiner, 1991.

RABEL, R. "Schêma in Plato's definition of Imitation". Ancient Philosophy, 16. 1996.

RINGBOM, S.. "Plato on Images". Theoria, 31. 1965.

SPINELLI, Miguel. Helenização e Recriação de Sentidos. A Filosofia na Época da Expansão do Cristianismo - Séculos II, III e IV. Porto Alegre: Edipucrs, 1998.

. Herança Grega dos Filósofos Medievais. São Paulo: Hucitec, 2007a.

- Questões Fundamentais da Filosofia Grega. São Paulo: Loyola, 2007b.

. "Sócrates no Tribunal: a tese do não-saber como estratégia de defesa". In: Boletim do CPA. IFCH/UNICAMP. Ano X, 19. Campinas, 2005.

"O exame de Aristóteles da proposição ontológica de Parmênides". In:

Revista Portuguesa de Filosofia. Braga, 1997. 